6-6-2013

\title{
On the Power of Music: Using 'Cosmos' and 'Anthropos' to Articulate a Holistic Approach to Discussing the Power of Music
}

Brian R. Cates

Cedarville University, bcates@cedarville.edu

Follow this and additional works at: https://digitalcommons.cedarville.edu/musicalofferings

Part of the Musicology Commons

DigitalCommons@Cedarville provides a publication platform for fully open access journals, which means that all articles are available on the Internet to all users immediately upon publication. However, the opinions and sentiments expressed by the authors of articles published in our journals do not necessarily indicate the endorsement or reflect the views of DigitalCommons@Cedarville, the Centennial Library, or Cedarville University and its employees. The authors are solely responsible for the content of their work. Please address questions to dc@cedarville.edu.

\section{Recommended Citation}

Cates, Brian R. (2013) "On the Power of Music: Using 'Cosmos' and 'Anthropos' to Articulate a Holistic Approach to Discussing the Power of Music," Musical Offerings: Vol. 4 : No. 1 , Article 3.

DOI: $10.15385 /$ jmo.2013.4.1.3

Available at: https://digitalcommons.cedarville.edu/musicalofferings/vol4/iss1/3 


\title{
On the Power of Music: Using 'Cosmos' and 'Anthropos' to Articulate a Holistic Approach to Discussing the Power of Music
}

\author{
Document Type \\ Article
}

\begin{abstract}
Music is an experience that is universal to all of mankind, no matter one's race, gender, culture, or socioeconomic status. Whether it's beholding one of Mahler's symphonies in Carnegie Hall or listening to the "No. 1 Top Single" on iTunes using headphones, one truth is evident: music moves. The statement "music moves" inherently possesses an implication of the 'cosmic' and the 'anthropic' nature of music - a holistic union of both mystery and humanity. This one truth has been the subject of an ongoing 2,000 year-old discussion that attempts to articulate the powerful reaction that results from experiencing music in all forms, beginning with the ancient Greeks of antiquity who possessed a cosmologically-grounded explanation to the power of music. However, as time moved forward, this cosmological, mysterious paradigm of the power of music slowly began to incorporate explainable and tangible anthropological articulations of the power of the music with respect to the human emotions, senses, and thoughts. This incorporation of anthropos reached a climax in the Renaissance era with the ushering in of humanism, which stripped away the mysterious and replaced the cosmologically-grounded explanation of music with the anthropologically-grounded view of naturalism. Since this profound departure from cosmos, society seems to be at a loss in articulating accurate reactions to music.

This paper offers two proposals with respect to musical thought, one for society at large and one for the individual. I assert in this paper that society, in general, needs to return to an appreciation of the cosmos, the answerable, and the mysterious in nature, and that the individual needs to commence thinking holistically with respect to music-incorporating both cosmic and anthropic thought. I have reached my conclusions, assertions, and propositions based on this thesis by critically analyzing both primary and secondary resources in the form of the historical documentation methodology.
\end{abstract}

\section{Keywords}

Cosmos, anthropos, power of music, humanism, holism

\section{Creative Commons License}

\section{(c) (†) $\ominus$}

This work is licensed under a Creative Commons Attribution-Noncommercial-No Derivative Works 3.0 License. 


\title{
On the Power of Music: Using 'Cosmos' and 'Anthropos' to Articulate a Holistic Approach to Discussing the Power of Music
}

\author{
Brian Cates \\ Cedarville University
}

Throughout history music has played an integral role in shaping both societies at large and individuals who are a part of these societies. Many of these individuals have sought not only to enjoy music by listening to it from an aesthetic paradigm, but by understanding it from a metaphysical one, probing its sonic depths and studying its emotive qualities, starting with the doctrines of music proposed by ancient Greek philosophers. However, from the doctrines of music in the ancient era up to the doctrines of music in the baroque era, one can observe a shift in the way music was perceived metaphysically. In spite of this shift, there remained a unifying idea: music moves. In this paper, I will attempt to show where this shift in musical thought occurred in history and explain its significance for present day lovers of music. By understanding the impact of this paradigm shift and having a more accurate way of approaching the perception of music in general, one is able to be more effective in realizing and appreciating the power of music in everyday life.

In order for a shift in thought to occur, there must also be a corresponding change in one's perspective of that thought. Jeremy Begbie says this about the importance of perspective: "One of the marks of what is called 'modernity,' or 'the modern age'...is that [a] cosmic perspective has largely been lost; indeed, it is often ridiculed and attacked....Thinking about music...has been marked by a shift from the cosmological to the anthropological, from justifying music in terms of the cosmos at large to justifying it solely in terms of human 
needs and aspirations." " From this quotation one can explicitly observe two distinct paradigms of musical perspective: cosmological and anthropological. Anny von Lange also identifies these two paradigms, saying, "No doubt...music — given a good performance - has the power to awaken the soul of earthly man to his higher nature." 2 This is a remarkable statement to make because it suggests that music possesses the capabilities of uniting these two dissimilar paradigms into a unique and more accurate understanding of music - a true holistic musical paradigm. Furthermore, N. T. Wright tangibly defines cosmos as "the differentiation between the [C]reator [G]od and the created order," while anthropos is "the human-centered version of [cosmos]. Humans are bipartite creatures, a combination of body and soul." 3 These two paradigms together represent the foundation by which philosophers have metaphysically attempted to understand the nature of music and its perception by listeners. Throughout this paper, I will expand upon these definitions of cosmos and anthropos by shedding light on how the nature of music was perceived by music philosophers from the ancient era to the baroque era, how they in turn used the paradigms of cosmos and anthropos to explain their perceptions, and show the role that these perceptions play in understanding the paradigm shift that took place in musical thought.

The Western music tradition can be firmly traced back to the teachings and philosophies of the ancient Greek philosophers. This group of individuals established a frame of reference for discussing the nature of music, its origins, and its ability to affect human beings. Pythagoras (570-495 BC) was arguably the first ancient Greek philosopher who began thinking of such things. He is credited with having discovered the underlying mathematical principles of music production, asserting that "harmonies must arise only from the relationship of whole numbers." 4 From this assertion he and his followers, known as Pythagoreans, believed that ratios and numbers were the key to unlocking the mysteries of explaining the universe. "They concluded

\footnotetext{
${ }^{1}$ Jeremy Begbie, Resounding Truth: Christian Wisdom in the World of Music (Grand Rapids: Baker Academic, 2007), 94.

2 Anny von Lange, Man, Music and Cosmos (Sussex: Rudolf Steiner Press, 1992), 15.

${ }^{3}$ N. T. Wright, The New Testament and the People of God (Minneapolis: Fortress Press, 1992), 253.

${ }^{4}$ Beekman Cannon, William Waite, and Alvin Johnson, The Art of Music (New York: Thomas Y. Crowell Co., 1960), 6.
} 
that all phenomena, spiritual and physical, were manifestations of the all-embracing law of numerical proportions. Number determined not only the quantities, but also the qualities of objects." 5 This revolutionary conclusion led Pythagoras to devise a theory known as the Music of the Spheres, "the belief that planets and stars of different sizes emit different pitches, generating a huge, but inaudible, cosmic music." 6

Despite a heavy emphasis on a cosmic perspective, there is also a hint of anthropos stirring in the Pythagorean view of music. Legend has it that a set of metal hammers of varying mass being hit at different times, naturally producing different tones and pitches, sparked Pythagoras's thinking of music and sound on a cosmic level. This deeply human experience of a fairly simple acoustic phenomenon is what brought the ideas of music and sound production into the mind of Pythagoras. Thus at the heart of the Music of the Spheres is an honestly and deeply human experience of simply hearing and responding to different musical pitches.

Begbie articulates the Pythagorean perspective of music in this way: "The Pythagorean vision is...mathematical through and through: the relationship of planets and stars in motion, the relationship of one part of creation to another, of soul to body, of one person to another-all these and other relationships were believed to be held together by, and subject to, a single cosmic mathematics."7 In other words, the anthropos of the individual's soul and body as well as individuals together in a society are held together by, and subject to, cosmos.

With Plato (427-347 BC) one can observe a more anthropological take on the nature of music; he discusses it with respect to the human senses and emotions. "Music gives us not only a model of harmonious balance, unity, and integrity, it actually implants cosmic harmony into the soul of humans." In his Republic, Plato, a Pythagorean himself, states, "as the eyes are designed to look up at the stars, so are the ears to hear harmonious motions; and these are sister sciences-as the Pythagoreans say." 9 In other words, Plato is using the human senses of

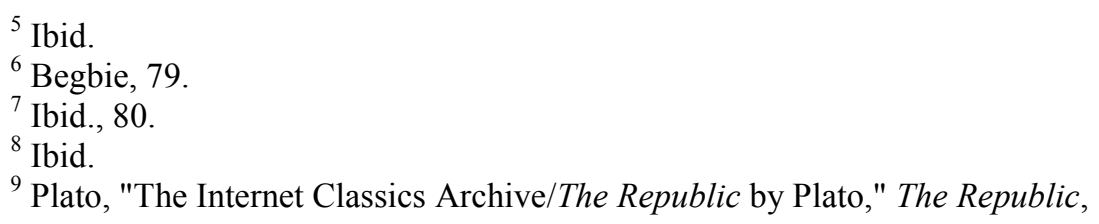


seeing and hearing with regard to cosmological thought, empirical observation, and "harmonious motions," a direct reference to the music of the spheres.

Plato also references the doctrine of ethos, the notion that it is possible for music to affect one's behavior. Plato strongly affirmed this doctrine so much that it caused him to exhibit a "marked anxiety about music's emotional power. Music can (and ought to) calm the emotions... [b]ut it can also act...to do just the opposite and disrupt the soul." ${ }^{10}$ Even though Plato still held the overall cosmological view of music which Pythagoras instituted, he also took a more anthropological approach to understanding and explaining musical thought.

Lastly, Aristotle (384-322 BC) further added anthropic dimensions to the overall Ancient Greek view of music with respect to Greek culture, the doctrine of ethos, and education. It is clear that Aristotle was still cosmologically minded; his treatise On the Heavens outlines the nature of cosmology and astronomy in great detail. Jonathan Barnes explains Aristotle's disposition on the cosmos by saying that celestial bodies are made quintessence, meaning that "the heavenly bodies, being divine, must therefore be alive and intelligent." 11 However, Aristotle makes a striking comparison of cosmos to anthropos when he states that although "we are inclined to think of the stars as mere bodies or units, occurring in a certain order but completely lifeless; whereas we ought to think of them as partaking of life and initiative." ${ }^{\prime 2}$ This is a crucial statement to consider; Aristotle is directly comparing the cosmos with anthropos - comparing the divine, quintessent stars with life itself. This equality of cosmos and anthropos naturally affects the way in which Aristotle views music, even with respect to the role of music in society. $\mathrm{He}$ "[regards] it as one among many aspects of natural phenomena.... The key to a good society lay in the nature of man himself; the role of music was to support the virtuous elements of his nature." 13

accessed May 31, 2013, http://classics.mit.edu/Plato/republic.8.vii.html.

${ }^{10}$ Begbie, 81 .

${ }^{11}$ Jonathan Barnes, Aristotle: A Very Short Introduction (Oxford: Oxford University Press, 2000), 102.

${ }^{12}$ Aristotle, On the Heavens. Translated by W. K. C. Guthrie (Cambridge:

Harvard University Press, 1986), 207-208.

${ }^{13}$ Sharon Scholl and Sylvia White, Music and the Culture of Man (New York: Holt, Rinehart and Winston Inc., 1970), 17. 
To sum up the ancient Greek perspective on the nature of music, major Greek philosophers all recognized that music was something grandiose, mysterious, cosmic, divine, yet at the same time perceptible, accessible, tangible, and anthropic. They all approached music from this holistic musical perspective, and it is this perspective that laid a solid foundation for future music philosophers who sought to understand the nature of music.

Boethius (AD 480-524), an early Roman philosopher, poet, and politician of the Middle Ages, is an extremely important figure to discuss with respect to understanding humanism in the renaissance. $\mathrm{He}$ revisited the Pythagorean, Platonic, and Aristotelian ideas of cosmos and anthropos in his De institutione musica (The Fundamentals of Music), stating that there are three levels to the hierarchy of music: (from top to bottom) musica mundana (the universe's mathematical rationalization); musica humana (the body and soul of humans in harmony); and musica instrumentalis (music that is physically perceived). Intriguingly, these three hierarchies of music together encompass the overall ancient Greek disposition towards music. Musica mundana can be compared to Pythagoras, musica humana to Plato, and musica instrumentalis to Aristotle.

Another reason for Boethius's importance in discussing the background to the humanism movement of the renaissance is because of his involvement with the liberal arts. The word "liberal" is derived from the Latin word liber, which means "free." As such, the liberal arts were considered more than merely receiving education; it was a free way of life, a habitus, "a quality enabling a faculty" that was even deemed to be a "second nature." 14 Martianus Capella, in the fifth century, discussed the notion of there being seven liberal arts: grammar, dialectic, rhetoric, geometry, arithmetic, astronomy, and music. These seven liberal arts were divided into two sections called the quadrivium and the trivium. Geometry, arithmetic, astronomy, and music were considered a part of the quadrivium, while grammar, logic, and rhetoric were considered part of the trivium.

Music as a liberal art is rather intriguing to study, since it endured a shift from the quadrivium to the trivium. Boethius himself considered

\footnotetext{
${ }^{14}$ Fr. Hervé de la Tour, "The Seven Liberal Arts." Edocere.org Home page, accessed November 2, 2012,

$<\mathrm{http}: / /$ www.edocere.org/articles/7_liberal_arts.htm $>$.
} 
music as part of the quadrivium and music was classified as such until the twelfth century. However, by the thirteenth and fourteenth centuries music had been "more apt to be classed with the [trivium]. Music was now to be regarded as a branch of poetic eloquence, an art of persuasion and disclosure." 15 In fact, Giulio del Bene in 1586 made a formal proposition that music be transferred from the quadrivium to the trivium. A shift had occurred, later to be called a 'renaissance' or 'rebirth.'

The renaissance directly correlated with the development of humanism, the study of the humanities and things pertaining to humans acquiring knowledge. Since scholars were concerned mostly with human knowledge and the power of the human spirit, there was no more need to possess a cosmological paradigm as an integral part of musical thought. Rather, it was replaced with the strong anthropological foundation of attempting to reach cosmos through the powers of reason and understanding. Pico della Mirandola, in his oration On the Dignity of Man says this: "We have set thee at the world's center that thou mayest from thence more easily observe whatever is in the world. ...Thou shalt have the power, out of thy soul's judgement, to be reborn into the higher forms, which are divine." 16

Man in all his anthropic power was raised to be a god-like figure who needed no other paradigm of understanding, explaining, and expanding of thought - he became the understanding, the explanation, and the expansion of thought. Thus when one leaves the renaissance era and enters the baroque era with the Doctrine of the Affections, musical thought is articulated purely in terms of anthropos attempting to reach toward cosmos, especially with respect to early baroque opera. Indeed, the cosmic perspective once held by the Ancient Greeks seemed distant and almost non-existent as one enters the baroque era.

Humanism impacted all areas of thought, including scientific and cosmic thought. "The man of the seventeenth century was called upon to reject all his former notions of the universe and to abandon a cosmological scheme which not only had determined how he

\footnotetext{
${ }^{15}$ Richard Taruskin and Christopher H. Gibbs, The Oxford History of Western Music. College ed. (Oxford: Oxford University Press, 2013), 170.

${ }^{16}$ Ernst Cassirer, Paul Kristeller, and John Randall, Jr., eds., The Renaissance Philosophy of Man: Selections in Translation (Chicago: University of Chicago Press, 1948), 225.
} 
interpreted nature but had also sustained his religious belief." 17 Monumental scientific discoveries made by those such as Copernicus attacked the very mystery of the motion of the spheres in claiming that the earth was not in fact the center of the universe; rather, it revolved around the sun. With the help of Galileo's publishing of The Astronomical Messenger, Copernicus's theory finally became accepted as truth in 1610. "The safe, snugly enclosed world of the past had suddenly crumbled away, exposing man to an unfamiliar sky." "18 This "unfamiliar sky" was a revolutionary way of viewing the world for those in the seventeenth century. Kepler articulated this concept as follows:

Nothing can be known completely except quantities or by qualities. And so it happens that the conclusions of mathematics are most certain and indubitable.... Just as the eye was made to see colours, and the ear to hear sounds, so the human mind was made to understand, not whatever you please, but quantity. ${ }^{19}$

Humanism had a similar effect on musical thought of the seventeenth century. Composers associated with the Florentine Camerata sought to imitate the rhetoric and oratory doctrines of the ancient Greeks, placing a heavy emphasis on rhetorical, speech-like expression in their music and how it related to expressing one's emotions. Edward Lippman says this about oratorical style and music with respect to the Ancient Greeks:

The fundamental relationship between oratory and music is found in the swaying of the feelings;...music is a servant of oratory not only in reinforcing its emotional effects but in the training of the orator as we $11^{20}$

Composers of the renaissance envisioned themselves as men who spoke

\footnotetext{
${ }^{17}$ Beekman Cannon, William Waite, and Alvin Johnson, The Art of Music (New York: Thomas Y. Crowell Co., 1960), 216.

${ }^{18}$ Ibid., 215.

${ }^{19}$ Edwin Burtt, The Metaphysical Foundations of Modern Science. Rev. ed. (Atlantic Highlands, NJ: Humanities Press International Inc., 1992), 68.

${ }^{20}$ Edward Lippman, Musical Thought in Ancient Greece (New York:

Columbia University Press, 1964), 132.
} 
through their music; they applied the ancient Greek view of rhetoric and oratory to conveying emotions in their music. Overall, the impact that humanism had on musical thought throughout the renaissance almost eliminated the ancient Greek holistic foundation of cosmos and anthropos, and laid an altogether new foundation for articulating music in purely anthropological terms in the Baroque era.

Musical thought was discussed in terms of the power of music over human emotions and sensations in the baroque era. Composers and music philosophers sought to return to ancient Greek musical thought, which is evident when discussing the Doctrine of the Affections.

Unquestionably, the Doctrine of the Affections has had one of the most profound effects on musical thought in all of music history. It was one of the characteristic features of music composed in the baroque era, along with the introduction of the basso continuo and a polarized texture between the top and bottom voices. The idea behind the Doctrine of the Affections is that a single movement of music should have only one 'rationalized' Affekt, and having more would lead to chaos. This is an important concept to begin with, because it reveals an aspect of ancient Greek thought. The affekts that are stirred up within humans while listening to a piece of music are not merely emotional excursions; rather, they are "rationalized" experiences. These "rationalized" experiences, or affekts, are also known as passions. There are fundamentally six passions that may be stirred and set in motion within a human being: wonder, love, hatred, joy, sadness, and desire. Another aspect of ancient Greek thought that was at the foundation of the Doctrine of the Affections was the concept of motion, observed by Aristotle. In his Der critische Musicus, Johann Scheibe insists that music "is to move the spirit, in particular to rouse or still the passions." ${ }^{21}$ Similarly, Bernard Lamy in his L'Art de bien parler states: "Men are not to be acted upon but by the motion of their passions....While we are without passion, we are without action; and nothing moves us from this indifference, but the agitation of some passion." 22 It is from this concept of motion with respect to the passions that the word emotion comes. The Doctrine of Affections is what led Baldesar Castiglione to say:

\footnotetext{
${ }^{21}$ The Art of Music, 253.

${ }^{22}$ Ibid., 251.
} 
Music...so full of art, ready, intense, inspired and of such varied melodies, that the spirits of the hearers are all moved and fired...[or] by a quiet way and full of flexible smoothness makes souls tender and pierces them, implanting sweetly in them a delightful passion. $^{23}$

From the ancient era to the baroque era, there have been many changes in perspective on the nature of music. However, as one can see, the concept of motion never changed; that is, both the ancient Greek and Baroque music philosophers both recognized that music moves. In the ancient Greek era and the Middle Ages, music itself was even ushered into existence by means of planetary motion - a mystery. Once in the baroque era, this perspective is virtually eliminated and instead replaced with music moving man's emotions and passions. Both are true and necessary for a complete understanding of the nature and power of music.

The proclamation "I think, hence I am," made by René Descartes, is the coup de grace of all anthropological thought and the apex of all humanistic philosophies, for it implies that the very existence of humanity and mankind itself is found within itself. The cessation of cosmological thought due to humanism in the seventeenth century brought about musical reactions being articulated purely in terms of human emotions, sensations, and metaphor. The ancient Greek musical thought consisted of a cosmic foundation, explaining and understanding physical phenomena. It is interesting to note that if one removes cosmos from the ancient Greek holistic paradigm, one is left with the Doctrine of the Affections.

In light of this shift in musical thought, here are two brief concluding thoughts. First, our society needs to cultivate a thirst for the 'mysterious' and 'the unknown.' The reality is that all the answers have not been found, and man is not autonomous. The mystery of the cosmos has a direct influence on anthropos. Aristotle referred to this force as the "unmoved mover." Perhaps this is the force which moves when one listens to music. Second, the individual should have a holistic mindset when thinking about the world, especially music. Musical thought, as discussed above, contains elements of both cosmological

\footnotetext{
${ }^{23}$ Robert Donington, A Performer's Guide to Baroque Music (New York: Charles Scribner's Sons, 1973), 19.
} 
and anthropological thought. Maybe when we listen to music, we will no longer perceive it as something that merely moves the emotions, but also perceive it and appreciate it as part of the many mysteries of the universe that impact everyday life, even turning on the radio and listening to music while driving down the highway. It is my hope that the reader will come to appreciate the value of approaching musical thought as being a combined paradigm of cosmos and anthropos-a holistic paradigm of understanding the nature and power of music.

\section{Bibliography}

Anderson, Warren D. Ethos and Education in Greek Music.

Cambridge: Harvard University Press, 1966.

Aristotle. On the Heavens. Translated by W. K. C. Guthrie. Cambridge: Harvard University Press, 1986.

Barnes, Jonathan. Aristotle: A Very Short Introduction. Oxford: Oxford University Press, 2000.

Begbie, Jeremy. Resounding Truth: Christian Wisdom in the World of Music. Grand Rapids, MI: Baker Academic, 2007.

Bukofzer, Manfred. Music in the Baroque Era. New York: W. W. Norton \& Co., 1947.

Burtt, Edwin A. The Metaphysical Foundations of Modern Science. Rev. ed. Atlantic Highlands, NJ: Humanities Press, 1980.

Cannon, Beekman C., William G. Waite, and Alvin H. Johnson. The Art of Music. New York: Thomas Y. Crowell Co., 1960.

Cassirer, Ernst, Paul Oskar Kristeller, and John Herman Randall, Jr., eds. The Renaissance Philosophy of Man: Selections in Translation. Chicago: University of Chicago Press, 1948.

Donington, Robert. A Performer's Guide to Baroque Music. New York: Charles Scribner's Sons, 1973. 
Hervé de la Tour, Fr. "The Seven Liberal Arts." Edocere.org Home page. Accessed November 2, 2012.

$<$ http://www.edocere.org/articles/7_liberal_arts.htm>.

Lange, Anny von. Man, Music and Cosmos. Sussex: Rudolf Steiner Press, 1992.

Lippman, Edward A. Musical Thought in Ancient Greece. New York: Columbia University Press, 1964.

Plato. "The Internet Classics Archive/The Republic by Plato." The Republic. Accessed May 31, 2013.

http://classics.mit.edu/Plato/republic.8.vii.html.

Scholl, Sharon, and Sylvia White. Music and the Culture of Man. New York: Holt, Rinehart and Winston Inc., 1970.

Simpson, Peter. The Politics of Aristotle. Chapel Hill: University of North Carolina Press, 1997.

Taruskin, Richard, and Christopher H. Gibbs. The Oxford History of Western Music. College ed. Oxford: Oxford University Press, 2013.

Thomson, James C. Music through the Renaissance. Dubuque, IA: W.C. Brown Co., 1968.

Wright, N. T. The New Testament and the People of God. Minneapolis: Fortress Press, 1992. 